\title{
A CONSTITUIÇÃO DO DADO EM ESCRITOS SOBRE A PRÁTICA DE ENSINO DE LÍNGUA: ANÁLISE DISCURSIVA DE RELATÓRIOS E ARTIGOS
}

\section{HOW DATA WORK IN WRITTEN TEXTS ON LANGUAGE TEACHING PRACTICES: DISCURSIVE ANALYSIS OF REPORTS AND PAPERS}

\section{Thomas Massao Fairchild ${ }^{*}$}

\section{RESUMO}

Apresentamos resultados parciais de um projeto de pesquisa em que vimos discutindo o papel da escrita na formação de professores. A premissa geral é a de que escrever sobre a aula pode ser um trabalho pelo qual o professor produz, para si e para outros, dados que permitem levar adiante, por meio de uma atividade posterior, a reflexão e os posicionamentos assumidos por ele no próprio momento da aula. Neste artigo, focamos a exposição de dois aspectos dessa pesquisa: a análise de tipo "polifônico", centrada no deslindamento das "vozes" que compõem o discurso escrito sobre a aula, baseada nas ideias de O. Ducrot; e o questionamento sobre o que a configuração do enunciado pode dizer acerca do "sujeito empírico" responsável por ele, afastando-nos de Ducrot em favor de Bakhtin. Os dados discutidos aqui representam dois universos: textos escritos por estudantes cursando disciplinas de prática em cursos de Letras e artigos acadêmicos sobre o ensino de língua publicados em periódicos da área. Apontamos três problemas comuns a ambas as esferas: a) o uso de termos "vicários" em substituição ao registro de informações concretas; b) a inserção de discursos citados como enunciados a que se responde e não como dados que se analisam; c) conclusões sobre o ensino que não se vinculam aos dados ou análises apresentadas. Sintetizamos os resultados das análises afirmando que, quando se trata de discutir o que se passa na sala de aula, mesmo quando se escutam as "vozes" que emanam desse espaço, não se lhes confere um estatuto claro de dado, dando-se aos discursos citados tratamentos diversos e fazendo com que o discurso resultante seja inconsistente enquanto análise da aula.

Palavras-chave: Formação de professores. Ensino de língua. Polifonia. Dialogismo.

\section{ABSTRACT}

We present partial results of a research project in which we discuss the function of writing in teachers' education. The general premise is that writing about a class may be an activity through which the teacher produces, to himself and to others, data that will allow him to keep working on the ideas and positions assumed by him when in class. In this paper we focus on two aspects of this research: the "polyphonic" analysis centered on unfurling

\footnotetext{
* Universidade Federal do Pará, Belém (PA), Brasil. tmfairch@yahoo.com.br 
the "voices" that make up a written discourse about the class, based on the ideas of O. Ducrot; and the questioning of what the configuration of the enunciate may show about the "empirical subject" responsible for it, diverging from Ducrot in favor of M. Bakhtin's ideas. Our data comprise two universes: texts written by Language Arts students during their in-school training and papers on the teaching of Portuguese published in academic journals. We point out three problems that are common to both kinds of data: a) the use of "weasel words" in the place of concrete information; b) the insertion of cited discourses as enunciates to which one answers instead of as data that one analyses; c) conclusions about the class that do not result from the data analysis that is shown. We synthesize our results by stating that, when it comes to discussing what goes on in the classroom, even though one might listen to the "voices" that come from there, such voices hardly receive any treatment as data and are responded to in different ways; the resulting discourse is thus inconsistent as far as an analysis of the class.

Keywords: Teachers' education. Language teaching. Polyphony. Dialogism.

\section{INTRODUÇÃO}

Neste trabalho apresentamos alguns resultados parciais do projeto "A escrita sobre as práticas de ensino em cursos de Licenciatura do Brasil, da Costa Rica e de Honduras: registro, análise e produção de conhecimento" (CNPq 458449/20148). O projeto discute como a escrita comparece nas práticas de formação de professores em instituições dos três países envolvidos e problematiza a relação entre o processo formativo do docente e as formas que sua escrita adquire nesse processo. Pergunta-se como o professor em formação se relaciona, por meio da escrita, com o conhecimento que sustenta sua prática, e de modo mais específico, se e como essa escrita chega a produzir algum conhecimento.

O modo como utilizamos o termo "conhecimento" requer um esclarecimento. Consideramos que um texto escrito por um professor pode atestar sua relação com o "conhecimento" a partir de dois vieses. No primeiro, indagamos o que um texto demonstra dos conhecimentos individualmente adquiridos por aquele que o escreveu; neste caso, faz-se uma leitura semelhante à que um professor realiza dos trabalhos de seus alunos, e "conhecimento" se refere ao grau de apropriação do autor sobre uma fortuna intelectual precedente. Mas também podemos nos aproximar de um texto indagando o que ele apresenta de inédito para a comunidade a que se destina e, nesse caso, lê-se o texto como quem consulta uma bibliografia de pesquisa. O termo "conhecimento" passa a se referir àquilo que um autor teria acrescentado ao estado de conhecimento do qual partiu, e não simplesmente à sua familiaridade com esse cabedal.

Temos interesse pelos dois aspectos do problema. Ao analisar textos escritos por professores, indagamos tanto sobre a qualidade de suas aprendizagens na área 
em que estão se formando quanto sobre o ineditismo daquilo que apresentam como resultado de seu trabalho. Não obstante, sabemos que a primeira perspectiva é amplamente contemplada na bibliografia sobre ensino de língua materna e corresponde ao entendimento mais comum do que seria "formar-se", de modo que temos optado por explorar com mais frequência o segundo viés. Concentramo-nos em perguntar em que medida a formação prática do docente é realizada enquanto uma prática de pesquisa sobre o ensino, e em que medida a experiência do professor em formação resulta, para além de sua própria aprendizagem, num movimento que permita à própria área continuar avançando.

Investigamos esse problema em um corpus composto por textos tais como relatórios de estágio, portfólios, planos e roteiros de aula, ensaios e uma variedade de outros materiais semelhantes escritos por professores em formação. Os textos do corpus têm em comum o fato de serem registros ou discussões acerca de atividades de ensino das quais o professor participou. Uma vez que o projeto possui um componente de pesquisa-ação, espera-se apontar alguns parâmetros sobre o que se esperar e o que exigir da escrita de futuros docentes com base nos problemas circunscritos pela análise e nos resultados alcançados por meio da intervenção direta dos pesquisadores.

As análises do corpus tem se organizado a partir de três eixos que podem ser descritos por meio de perguntas: a) de que modo são registrados no texto dados sobre a aula?; b) de que modo surgem no texto procedimentos de manejo e análise dos dados registrados?; c) de que modo o texto apresenta conclusões tiradas da análise dos dados? Esse esquema tem se mostrado útil para nós por dois motivos. Primeiro, ele nos desembaraça de uma análise de tipo textual (problematizando questões como coerência, estilo, domínio das formas textuais típicas etc.) e nos permite passar diretamente à problematização do processo da escrita, tomado enquanto processo referencial, epistemológico ou argumentativo. Com isso, nos afastamos de qualquer preocupação em discutir a escrita do professor em formação enquanto um problema de "domínio" dos gêneros da escrita acadêmica. Em segundo lugar, as perguntas de pesquisa ajudam-nos a situar certos problemas em uma etapa ou aspecto específico da escrita, bem como mostram certos efeitos de encadeamento que um problema situado em uma etapa pode ter sobre a estruturação geral do discurso. Assim, por exemplo, temos constatado que grande parte dos relatórios recolhidos em pesquisa de campo (isto é, que não resultam da intervenção do pesquisador) são lacunares ou vagos ao registrar a aula, de modo que, quando há uma afirmação de caráter mais conclusivo (por exemplo, "os alunos não se interessam pela literatura"), não se 
encontra um dado que fundamente a conclusão, nem se encontram indícios claros de um percurso interpretativo que tenha levado a esse postulado.

De outra parte, temos nos visto instados a ampliar o corpus da pesquisa à medida que fazemos as mesmas perguntas aos textos acadêmicos que inicialmente nos servem como estado da arte - isto é, textos acadêmicos que pesquisam a escrita de professores em formação e têm relatórios ou textos similares como dados. Parte desses textos tem se mostrado muito semelhante aos textos escritos por estudantes, seja porque se propõem a discutir a escola a partir de dados recolhidos por estagiários, seja porque demonstram problemas semelhantes no tratamento que dispensam aos dados. Observamos em parte desses textos, por exemplo, a ausência ou caracterização insuficiente dos documentos apresentados como dados, a presença de paráfrases do conteúdo explícito dos relatórios no lugar de uma discussão ou análise, a adoção de procedimentos de análise diferentes sobre um mesmo dado, a apresentação de conclusões que não derivam da análise ou não se sustentam no dado etc.

Essa percepção nos leva a ampliar a pergunta anteriormente colocada para se chegar a outra, de maior abrangência: produz-se conbecimento nas licenciaturas? Com essa ampliação de escopo, colocamos a análise da escrita de professores em formação lado a lado com a análise da escrita de pesquisadores já formados, que não só ditam um modelo de conduta como ocupam uma posição na qual concorrem para consolidar certas funções muito concretas para escrita nesse campo.

Procuraremos discutir essa asserção comparando textos escritos por alunos (relatórios de estágio e afins) e textos escritos por pesquisadores (artigos publicados em periódicos acadêmicos). Para cada caso mostraremos três exemplos, a fim de ilustrar problemas que dizem respeito ao registro, aos procedimentos de análise e às conclusões postuladas a partir dos dados. Perguntamos, em ambos os casos, de que modo a escrita atesta um trabalho sobre a experiência (de estágio, no caso dos relatórios; e de supervisão de estágio, no caso dos artigos) e engendra a produção de conhecimento. No próximo item, esclarecemos os referenciais teóricos com base nos quais fazemos essa discussão aqui.

\section{ESCRITA, POLIFONIA E DIALOGISMO}

As análises realizadas neste trabalho lançam mão de basicamente dois autores - Ducrot e Bakhtin. Temos recorrido a ambos porque vimos percebendo que as maiores fragilidades dos textos que temos analisado dizem respeito ao manejo das 
"vozes" que comparecem (ou deixam de comparecer) no discurso do professor em formação. Esse aspecto deve ficar mais claro no item 2, quando passamos às análises.

Do primeiro autor, vamos nos valer do modelo de análise apresentado em Esboço de uma teoria polifônica da enunciação (1987a). Nesse texto, Ducrot desenvolve a tese de que o sujeito do discurso é um sujeito dividido entre várias instâncias. Há diferentes "seres" no discurso, agrupados por ele em duas grandes categorias - locutores e enunciadores". Todos eles se distinguem, em termos de "estatuto metodológico", daquilo que o autor nomeia como "sujeito empírico". Aquele que produz materialmente um discurso, o sujeito empírico, não é necessariamente aquele a quem se deve atribuir tal discurso - quando um estudante transcreve as palavras escritas pelo professor na lousa, durante uma aula de estágio, o estudante é o sujeito empírico responsável por digitá-las no relatório, mas não seu locutor, já que não apresenta essas palavras como sendo suas, mas do professor.

Ducrot descarta o sujeito empírico de sua teoria, bem como foge de toda tentativa de explicar o sentido de um enunciado por uma referência ao mundo ou a outros enunciados; é nesse ponto que divergimos dele, conforme veremos adiante. De todo modo, Ducrot faz uma distinção que consideramos importante com relação aos estatutos que um locutor pode assumir no enunciado. Por um lado, existem palavras que são remetidas a uma voz representada dentro do discurso; este sujeito a quem se remetem as palavras citadas é um locutor apresentando enquanto "ser do mundo" $(\lambda)$, topicalizado no interior do discurso. Por outro lado, há um locutor "enquanto tal" (L), que não surge como um ser representado dentro do discurso, mas responde pelo próprio enunciado em seu conjunto.

Em se tratando de relatórios de estágio ou artigos acadêmicos, podemos dizer que há um estagiário ou um autor que surge como locutor L e um conjunto de "personagens" (professores, alunos, autores citados...) que povoam seu discurso e tomam a palavra como locutores- $\lambda$. Podemos pensar também na situação comum em que o estagiário escreve sobre suas próprias ações e pensamentos durante as aulas, ou o autor de um texto acadêmico cita a si mesmo, escreve sobre suas atividades de pesquisa etc. Neste caso convém diferenciar o locutor do texto em si (L) daquele a quem se dá a palavra para um comentário $(\lambda)$ - mesmo que ambos correspondam a um mesmo "sujeito empírico".

\footnotetext{
1 Estamos cientes de que o próprio Ducrot reelaborou essas categorias e publicou diversos trabalhos em que revê as posições que retomamos aqui - por exemplo, revendo profundamente a noção de "ponto de vista" a partir da "teoria dos blocos semânticos" (DUCROT e CAREL, 2008), ou ainda, substituindo a noção de "enunciador" pela de "pessoa" (CAREL e DUCROT, 2010). Remetemos à versão "antiga" da teoria de Ducrot por opção deliberada.
} 
Além dos locutores, Ducrot inclui em seu modelo teórico uma segunda categoria de seres do discurso chamados por ele de enunciadores. Para definir do que se trata o autor faz duas metáforas. A primeira toma como referência o teatro: o locutor está para o personagem assim como o enunciador está para o autor. $\mathrm{O}$ autor, dessa forma, pode expressar seus pontos de vista (sua visão política, sua experiência estética etc.) não através de um enunciado "seu", mas por meio da obra, isto é, das palavras que são concretamente pronunciadas pelos atores (sujeitos empíricos) que encenam determinadas personagens (locutores). A segunda metáfora equipara os enunciadores à noção de "centro de perspectiva", que Ducrot busca em Genette. Em ambos os casos, o que sobressai é a ideia de que o enunciador "passa o seu recado" sem ser percebido como alguém que tenha um recado a dar - os enunciadores são aqueles seres aos quais não se conseguem atribuir, precisamente, quaisquer palavras em especial, mas que estão presentes na medida em que determinam o ponto de vista desde o qual o enunciado diz o que tem a dizer.

Esse esquema bastante intuitivo, entretanto, apresenta alguns problemas quando colocamos a análise linguística a serviço de uma compreensão dos processos formativos. Imagine-se, a título de exemplo, o caso do plágio - não se pode dizer que um enunciado plagiado pertença a um locutor $\lambda$ "oculto" no texto; trata-se de plágio justamente porque o enunciado apresenta certas palavras como sendo as $\mathrm{L}$, quando se sabe, por outros meios, que aquelas palavras pertencem a outrem. Esse "outrem", no entanto, é difícil de definir com base nas categorias de Ducrot. Estamos falando de outro sujeito empírico, capaz até mesmo de ações externas ao discurso, como a de esbofetear o plagiador ao encontra-lo na rua? Ou estamos falando apenas de outro L, responsável por um enunciado ao qual o plagiador faz alguma espécie de referência? Em nenhum dos casos o problema se resolve no âmbito puramente discursivo (da forma como Ducrot o concebe).

Poderíamos pensar, ainda, no caso de o plagiador, uma vez flagrado, desculparse e acrescentar ao seu texto aspas e indicações de nome de autor e página nos devidos lugares. Nesse caso o autor original passaria a figurar como $\lambda \mathrm{e}$, em termos puramente discursivos (novamente, no sentido de Ducrot), não se teria mais um plágio e sim um caso de citação. Mesmo assim, é provável que o texto modificado continuasse sendo alvo de ações empíricas muito parecidas às que receberia enquanto plágio - como sua retirada da fila para publicação em um periódico, sua reprovação em uma disciplina etc. O que essas reflexões nos mostram, portanto, é que, se vamos falar da formação de professores, é difícil manter o sujeito empírico fora da análise. 
Não vamos nos alongar sobre esse ponto, limitando-nos a indicar que é aqui que nos afastamos das preocupações de Ducrot a respeito de uma semântica puramente linguística, não-referencial, e nos reaproximamos da perspectiva dialógica original de Bakhtin. Para isso recorremos ao modo como o autor problematiza a relação entre signo linguístico e consciência a partir das críticas que faz às correntes da Psicologia europeia nos anos 1920. Bakhtin afirma que não há consciência anterior ao signo; o signo não reflete uma consciência subjetiva mas a produz no indivíduo. Retomaremos aqui apenas um aspecto dessa discussão e os relacionaremos ao modo como concebemos a escrita de relatórios - a polarização da "atividade mental" em torno do "eu" ou do "nós".

A fim de demonstrar que a consciência do homem é ideológica, Bakhtin argumenta que mesmo a tomada de consciência de uma sensação física como a fome não é uma percepção puramente biológica - ao contrário do animal, cuja fome é absolutamente solitária, o homem sente sua fome para a coletividade dos homens com que convive. Exatamente por isso, essa fome pode ser percebida conforme diferentes graus de consciência e diferentes orientações ideológicas.

\begin{abstract}
Suponhamos que um homem faminto tome consciência da sua fome no meio de uma multidão heteróclita de pessoas igualmente famintas, cuja situação se deve ao acaso (...). A atividade mental desse indivíduo isolado, sem classe, terá uma coloração específica e tenderá para formas ideológicas determinadas, cuja gama pode ser bastante extensa: a resignação, a vergonha, o sentimento de dependência (...). Suponhamos agora que o faminto pertença a uma coletividade onde a fome não se deve ao acaso, onde ela é uma realidade coletiva, mas onde entretanto não existe vínculo material sólido entre os famintos, de forma que cada um deles passa fome isoladamente. É essa, frequentemente, a situação dos camponeses (...). Em tais condições, predominará uma consciência da fome feita de resignação, mas desprovida de sentimento de vergonha ou de humilhação. Cada um diz a si próprio: 'já que todos sofrem em silêncio, eu também o farei'. (...) De maneira completamente diferente será experimentada a fome pelos membros de uma coletividade unida por vínculos materiais objetivos (batalhão de soldados, operários reunidos no interior da usina, trabalhadores numa grande propriedade agrícola de tipo capitalista [...]). (p. 115-116)
\end{abstract}

O que nos interessa reter dessa passagem não é apenas a tese bem conhecida de que a expressão interior, a consciência, seria resultante dos processos ideológicos que têm sua origem fora do indivíduo, mas a convicção bakhtiniana na existência de diferentes tipos ou "inflexões" da atividade mental que, por sua vez, "geram modelos e formas de enunciações correspondentes" (p. 116). Bakhtin afirma, ainda acerca do exemplo da fome, que a "atividade mental" se distribui numa espécie de espectro entre dois polos, a "atividade mental do eu" e a "atividade mental do nós". O polo do "eu" diz respeito às formas de discurso interior mais rudimentares, aos pensamentos inacabados, a tomadas de posição incompletas, aos devaneios etc. 
"Atividades mentais isoladas, ou mesmo sequências inteiras podem tender ao polo do eu, prejudicando assim sua clareza e sua modelagem ideológica, e dando provas de que a consciência foi incapaz de enraizar-se socialmente" (p. 115). O polo do "nós", por sua vez, diz respeito a um maior grau de discernimento e consciência, em que os pensamentos individuais (ou o "discurso interior") encontram formas de ancoragem mais firmes e estáveis nas formas sociais de discurso.

Ao defender o papel constitutivo da escrita na formação do professor, temos afirmado que escrever sobre o que se vivenciou na escola implica um movimento de retroação do sujeito sobre sua experiência. Nessa perspectiva, produzir um texto não consiste simplesmente em materializar um relato, mas implica um trabalho sobre a própria experiência que, ao ser discursivizada, também se modifica para o próprio sujeito. Pode-se considerar, usando os termos de Bakhtin, que por meio do ato de escrita o sujeito realiza um trabalho que leva sua percepção acerca dos fatos concretos de um polo centrado no "eu" - em que tendem a se expressar como sensações ou pensamentos vagos, dispersos - a um polo centrado no "nós" - em que adquirem maior concretude e coerência, e sobretudo, sujeitam-se às respostas de outros.

Essas afirmações de Bakhtin nos fazem considerar que relatos de estágio precários, genéricos, desorganizados ou carregados de clichês podem não estar prestando testemunho de uma simples "dificuldade de escrita" do aluno universitário, a ser corrigida pela oferta de modelos de textos e mesmo disciplinas inteiras dedicadas à prática da "escrita acadêmica". Elas nos levam a considerar que podemos estar às voltas com um problema muito mais sério - uma perda em termos do nível de "consciência" ou da "percepção" que o professor tem de seu campo profissional. A situação nos parece mais séria a partir do momento em que se constata que, no próprio nível dos trabalhos publicados dentro da área de ensino de língua - quando se sai do plano de uma "ideologia do cotidiano" e se passa ao que temos que considerar com o sendo os "discursos sociais" que moldam a própria "atividade mental do nós" - começamos a encontrar textos igualmente precários, genéricos, desorganizados e carregados de clichês. É exatamente nesse sentido que temos buscado analisar a escrita dos estagiários dentro de uma problematização mais ampla que é a própria capacidade da área de ensino de superar o estado de conhecimento em que se encontra e produzir, a partir de suas verdades atuais, as condições para que essas mesmas verdades possam ser superadas, ou ao menos confrontadas com dados concretos provenientes da escola. 


\section{A ESCRITA EM RELATOS DE ESTÁGIO}

Começamos por apresentar análises de textos escritos por estudantes universitários nas disciplinas de estágio. $\mathrm{O}$ excerto a seguir pertence a um plano de aula escrito por um aluno do curso de Letras de uma universidade da Costa Rica $^{2}$.

(1) Atividade de abertura: Primeiramente cumprimentaremos todos os alunos estimulando-os sobre a nova temática, em ordem, vamos perguntar a nível geral sobre sua experiência durante a semana passada de provas, com o objetivo de incentivá-los a continuar com otimismo o novo período.

Depois de passar a lista, comentaremos a atividade de apresentação e diagnóstico da aula anterior à semana de provas, resgatando aspectos importantes da análise de suas respostas.

De forma oral, perguntaremos aos alunos sobre os conhecimentos adquiridos em relação ao gênero literário conto, que viram com a obra "A abelha preguiçosa", texto que inclú́do [sic] na prova e realizaremos um diagnóstico oral sobre o trabalho extraclasse deixado pela professora antes da semana de provas sobre a obra "O carteiro do rei".

Este primeiro exemplo ilustra um problema que se tem mostrado muito frequente: a escrita do estagiário é insuficiente do ponto de vista do grau de especificidade das informações que presta a respeito da aula. Essa inespecificidade resulta de dois procedimentos que distinguimos, embora sejam bastante parecidos. O primeiro, ilustrado pelas passagens sublinhadas no excerto 1, consiste em fazer referências a certos materiais de ensino sem que os materiais em si estejam presentes no documento que os cita. Sabe-se (ou acredita-se) que foi feita uma "atividade de apresentação e diagnóstico", mas não se tem nenhuma informação sobre o teor dessa atividade nem se pode encontrá-la anexada ao plano de aula. O mesmo vale para "trabalho extraclasse" e para os dois contos mencionados, que só podem ser conhecidos se forem procurados fora do material apresentado pelo estagiário. Nesse caso, os termos sublinhados designam locutores $(\lambda)$ ou atos de fala, mas os enunciados correspondentes não surgem como um discurso citado em qualquer parte do conjunto do documento.

O segundo procedimento é mais problemático, pois não se trata apenas de um problema de citação ou referenciação. Ele está ilustrado pelos trechos em negrito: determinadas ações que exigiriam um registro ou planejamento mais minucioso são apresentadas por meio de uma expressão que as designa apenas de forma geral. A diferença em relação ao caso anterior é que, aqui, não se sabe se os termos em destaque estão fazendo referência a algo que existe fora do plano, como ato de um

2 A tradução do espanhol para o português é nossa. 
"sujeito empírico", e apenas não está incluído textualmente no documento ${ }^{3}$, ou se o termo vago recobre a inexistência de qualquer desdobramento concreto daquilo que supostamente designa. Assim, por exemplo, o termo "aspectos importantes da análise (de suas respostas)" surge no lugar de um parágrafo em que o estagiário poderia expor as respostas dos alunos e a análise que fez delas, destacando o que considerou mais importante - isto é, demonstrando o que preparou para esse momento particular de sua aula. Mesmo que acreditemos que as "respostas" dos alunos de fato existem enquanto documento concreto, parece-nos menos seguro supor que a "análise" dessas respostas tenha uma existência palpável - se há uma análise, ela não foi escrita (não consta no conjunto de documentos entregues pelo estagiário) e só existiria enquanto "resposta interior" do estagiário, ou enquanto discurso concreto do aluno no próprio momento da aula (mas, neste caso, de forma parcamente planejada).

Algo muito semelhante vale para todos os outros termos destacados com negrito no dado 1 : não sabemos de que modo o estagiário planeja fazer com que suas palavras funcionem como um "estímulo" ou "incentivo" aos alunos; que "perguntas gerais" ele pretende fazer; que "comentários" sobre a atividade pretende fazer; qual é o seu "diagnóstico" do desempenho dos alunos, e assim por diante. Temos nos referido a esse problema dizendo que ele decorre do uso indevido de termos "vicários", já que se trata sempre de um nome ou verbo de sentido mais geral que aparece como substituto de uma informação mais específica que não é prestada de forma explícita.

Além de recobrir a falta de um registro mais cuidadoso da aula, ocorrências textuais dessa natureza frequentemente promovem a veiculação irrefletida de discursos prévios sobre a escola, pois apresentam como pressupostos os elementos que deveriam ser objeto de discussão pelo professor em formação. Os "termos vicários" permitem ao escritor manter indefinidos pontos sobre os quais ele mesmo pode não ter uma compreensão clara, e isso aparentemente se dá, ao menos em parte das vezes, de forma involuntária. $\mathrm{O}$ autor do excerto 1 pode acreditar que suas impressões sobre as respostas dos alunos consistem em uma "análise" e que ela é suficiente para sustentar um debate produtivo com os alunos (é assim que o enunciado "descreve sua enunciação", se pensarmos em Ducrot) - mas se se trata

\footnotetext{
3 É preciso observar que o fato de um documento da aula estar incluído no texto do estudante (por exemplo, como anexo ou transcrição) não resolve o problema. O excesso de registros concretos da aula muitas vezes corresponde à ausência de reflexão sobre o que foi registrado. Se há uma vantagem desse estilo de escrita sobre o que exemplificamos no nosso dado, trata-se apenas de que a coleta de dados garante certo potencial para que o registro se desdobre numa análise.
} 
mesmo de uma análise, e não de avaliações ingênuas ou mesmo erradas sobre as respostas dos alunos, nem nós, nem o estagiário o sabemos, pois ele não entra em maiores detalhes ao planejar esse debate nem apresenta, em outros documentos, um registro de como esse debate efetivamente se desenvolveu. Nesse ponto, como se vê, o problema do "sujeito empírico" se coloca como extensão inevitável de uma análise inicialmente "discursiva" - trata-se mais de uma questão da "consciência" que se produz a respeito dos fatos narrados por conta dos próprios signos por meio dos quais esses fatos são narrados.

Passemos a um segundo caso. Observamos, embora com menos frequência, situações em que uma asserção (normalmente de tom avaliativo) é feita sobre a aula sem que se possa determinar a quem o seu conteúdo deve ser atribuído. Algumas vezes, por exemplo, encontramos comentários sobre um determinado aluno que não sabemos se são afirmações do estagiário, registros indiretos de uma fala do professor ou uma mistura de ambos, configurando uma espécie de discurso indireto livre. Trata-se de um problema relacionado ao modo como as vozes de diferentes locutores são representadas no texto. $\mathrm{O}$ dado a seguir é um caso particularmente interessante desse problema, pois, nessa passagem, o pensamento de uma pessoa é apresentado como motivação da ação de outra.

(2) Perguntou para turma que profissão pretendiam seguir? Alguns alunos responderam, uns queriam ser médico, engenheiro civil, astronauta, dentista etc. Notei durante essas perguntas que nenhum dos 45 alunos dessa turma queria ser professor, a professora ainda perguntou por que ninguém queria ser professor e alguns responderam "porque a professora ganha muito mal" e um outro aluno acrescentou "e ninguém gosta de professor de português". Confesso que nesse momento fiquei angustiada, mas como estava apenas observando não falei nada.

A questão aqui é a quem pertence a angústia que está sendo relatada. A estagiária afirma ser uma reação dela mesma, decorrente de sua avaliação a respeito das posturas dos alunos. Tanto é assim que, logo após fornecer os exemplos das carreiras almejadas por eles, a estagiária apresenta como um pensamento seu a observação de que ninguém quis ser professor - o verbo usado é "notei...", na primeira pessoa. Mas nos surpreende que, em seguida a esse pensamento, e portanto como uma espécie de consequência dele, quem pergunta aos alunos se ninguém pensava em ser professor não é a autora do pensamento inquietante, mas a professora.

Há pelo menos duas interpretações diferentes que podemos fazer desse enunciado; retomemos as categorias de Ducrot para esquematizá-las. Na primeira interpretação, mais favorável à estagiária, suporíamos que a professora indagou os alunos em um tom neutro, de forma casual. Nesse caso, a "postura crítica" presente no trecho 2, ainda que muito pouco desenvolvida, ficaria toda a cargo de um 
enunciador E1 cujo ponto de vista não teria nada a ver com o de 11, a professora, mas com o de L, a estagiária enquanto locutora do relato. Na segunda interpretação, E1 representaria o ponto de vista presente nas palavras de 11, a professora - isto é, a estagiária teria "notado" o pouco prestígio da carreira docente por conta das perguntas da professora e, a seguir, aderido ao mesmo ponto de vista.

O acabamento geral dessa passagem, a nosso ver, é mais favorável à primeira interpretação - a percepção "crítica" introduzida pelo verbo "notei" é colocada antes da informação de que a professora fez uma pergunta com o mesmo teor, o que nos leva a entender que a teria antecedido. Por outro lado, um princípio de verossimilhança parece favorecer mais a segunda interpretação.

O recurso às categorias de Ducrot nos permite apontar um último fato interessante sobre essa passagem - é que os comentários "críticos" da estagiária têm pelo menos dois estatutos distintos no tocante à enunciação. Parte da "crítica" é facilmente percebida como uma "crítica" relatada: L, a estagiária enquanto autora do relatório, narra a perspicácia e a angústia de 12, a estagiária enquanto personagem que observa a aula. A tomada de posição está, portanto, a cargo de 12 - se há uma "análise" dessa situação, ela foi feita como parte do ato de observar e não como parte do ato de escrever o que se observou. Por outro lado, ao menos uma parte da "crítica" é assumida por L quando transcreve as duas respostas dos alunos que constam no relatório. Sobre essa componente "crítica" assumida por L, no entanto, podemos nos perguntar se se trata apenas de uma "crítica" aos alunos, ou também à professora. A expressão "confesso que" e a negação "não falei nada" introduzem ressalvas cujo teor não é totalmente claro. Temos que nos perguntar o que esse enunciado "subentende" - que os alunos foram desrespeitosos; que a professora não fez nenhum comentário sobre as respostas dos alunos; ou que, na opinião da estagiária, a professora não poderia ter deixado de fazer algum comentário sobre as respostas dos alunos?

O fato de que não disponhamos de esclarecimentos para essas dúvidas não constitui, para nós, apenas um problema "de escrita" em sentido textual. Aqui abandonamos Ducrot em favor de Bakhtin - não interessa considerar como o enunciado descreve sua enunciação, mas como o enunciado concorre na produção da tomada de consciência do sujeito sobre aquilo que designa por meio dos signos. $\mathrm{O}$ que a ambiguidade do excerto 2 nos mostra é que a fala da professora não é escutada pela estagiária enquanto dado, mas enquanto um enunciado de outrem ao qual ela responde (caso se trate de uma crítica à professora) ou com o qual ela faz coro (caso se trate de uma crítica apenas aos alunos).

Vejamos agora uma terceira situação. 
(3) Ao identificar esse problema, conversei com a professora e chegamos a uma conclusão que eles precisavam ler mais, ser mais atenciosos e que a utilização indevida de celulares e muitas conversas atrapalham na concentração deles, o que leva, portanto, a erros gramaticais. Percebi essa dinâmica de sala de aula indo até algumas carteiras em que estavam os alunos que conversavam assuntos diferentes do tema da aula da professora. Foi neste momento que tive a certeza de que eles estavam mais preocupados em ficar falando em facebook, desenhos, filmes que estavam estreando no cinema, etc, e não estavam dando importância para poesia

Nesse exemplo, temos um problema relacionado à maneira como o estagiário veicula conclusões a respeito do que observa. Duas expressões sublinhadas ("chegamos a uma conclusão" e "tive a certeza") introduzem os trechos em negrito como sendo resultado da reflexão do estagiário sobre suas experiências; no primeiro caso a conclusão é assumida em conjunto com o professor e, no segundo caso, é mostrada como sendo um pensamento individual. O problema está em que as conclusões do estagiário são introduzidas de forma sumária, sem que sejam mostradas evidências que as sustentem ou permitam que sejam discutidas. Além disso, em ambos os casos as conclusões não resultam da realização de um procedimento que seja esclarecido ou justificado; o estagiário salta bruscamente da identificação do dado à sua interpretação definitiva. Ao introduzir sua primeira conclusão, a única informação que o estagiário presta sobre o percurso interpretativo é a de que houve uma "conversa" entre ele e o professor, mas o próprio teor dessa conversa e a forma como, conversando, teriam chegado juntos à conclusão, é omitida do relatório. No segundo caso, o estagiário assevera ter caminhado pela sala para fazer observações mais precisas, que por sua vez teriam lhe "dado a certeza" do que afirma a seguir, mas o que precisamente foi observado por ele não consta no relato - pode-se apenas supor que ele tenha visto alunos acessando redes sociais e vendo desenhos animados nos celulares, mas neste caso o que é nomeado como conclusão é na verdade a própria evidência concreta.

Como conclusão parcial, os relatórios analisamos mostram três situações: a) o uso de "termos vicários" dificulta que certos aspectos da escola sejam postas em discussão; b) toma-se a palavra do agente que está na escola como enunciado ao qual se responde e não como dado a ser analisado; c) tiram-se conclusões arbitrárias sobre a escola sem se sentir obrigado a esclarecer os procedimentos que levaram a tal.

No próximo item procuraremos mostrar que os mesmos problemas podem ser encontrados na produção acadêmica que trata da formação de professores tomando relatórios de estágio como dados. 


\section{A ESCRITA EM TEXTOS ACADÊMICOS}

O excerto abaixo é um fragmento de um artigo científico publicado em 2012 num periódico brasileiro de circulação nacional.

(4) Produzidos nas disciplinas de estágio supervisionado, com atividades na universidade e na escola de educação básica, as configurações dos relatórios focalizados reproduzem a complexidade característica desses contextos, promissores espaços para investigação científica, dados os atores de natureza diversa em interação a serem ainda mais conhecidos (AUTOR, 2011b; AUTOR e COAUTOR, 2011). Conforme G., M. e R. (2009: 208), "entende-se o estágio como uma oportunidade de inserção numa realidade, no caso escolas de educação básica, permitindo a confrontação do saber acadêmico com o saber da escola, permitindo aos estudantes aprender como se dão as relações de trabalho.

Nesse excerto, todas as expressões em negrito funcionam como termos vicários, mas apenas a primeira ("configurações dos relatórios") será efetivamente especificada ao longo do texto (que consiste numa proposta de descrição do "gênero relatório de estágio"). Não há maiores especificações sobre qual é a "complexidade" do contexto ou como se configura o "espaço para investigação" - pode-se, no máximo, entender que nos textos citados como referência ao fim do período se encontrem essas informações. É interessante notar, em todo caso, que na sequência há uma citação direta de outro texto ("conforme G., M. e R.") dentro da qual continuam a surgir termos vicários - "numa realidade", "saber acadêmico", "saber da escola" e "como se dão as relações de trabalho" - que requereriam uma explicação do autor que os cita ou a continuidade da citação. Isso sugere que a ausência de definições mais precisas é um fenômeno em cascata, que não se resolve com a remissão a outros textos.

O efeito desses termos vicários não deixa de ser o de dar a entender que haveria consenso entre autor e leitor com relação ao sentido de certas expressões. Trata-se de um recurso que tem forte valor argumentativo, semelhante ao que Ducrot (1987b) caracteriza com relação à pressuposição - tornar mais difícil contestar parte do conteúdo enunciado ${ }^{4}$. Se relermos o excerto 4, é relativamente fácil aceitar que existam diferentes pontos de vista sobre o que é o estágio, mas

4 Mas, diferentemente do que diz Ducrot, neste caso o efeito de "pressuposição" não está inscrito na forma linguística e sim numa remissão do enunciado a outro enunciado. Com isso estamos mais perto de uma posição como a de Pêcheux (1995, p. 102 ss.) a respeito do "pré-construído" e da ideia de "formação discursiva" como conjunto de regras que determinam o que poderia ser a paráfrase de um enunciado. 
contestar a afirmação de que o estágio é uma "inserção numa realidade" é bem mais difícil pelo modo como o texto foi escrito.

Insistimos em afirmar que a questão levantada pelo uso de termos vicários, para nós, não tem a ver com a habilidade do escritor, mas com a constituição de uma "consciência de classe" que molda a "atividade mental do nós" no sujeito. Do ponto de vista do leitor do trecho 4, compreender qual é a posição do autor sobre o estágio requer saber identificar, por quaisquer outros indícios, quais são os enunciados anteriores em que se poderia, ao menos, começar a procurar uma definição explícita. Concordar com o autor pelo conteúdo "posto" do enunciado (ao qual, como dissemos, é difícil fazer muita oposição) sem ter aceso às posições "pressupostas" nos termos vicários (que recobrem uma ideia central de sua argumentação) sujeita o leitor a pensar que concorda com um texto com o qual pode não concordar ou, numa situação pior, concorda-se - mas não se sabe ao certo com quê.

Vejamos agora como o segundo problema levantado a partir da análise relatórios de estágio - a tomada das palavras do agente que está na escola como enunciado a que se responde, e não como dado que se analisa - se mostra em um texto acadêmico.

(5) De acordo com Fulano e Beltrano (2011, p. 8):

Apesar da aparente "bagunça", interpretação feita por muitos professores diante das falas dos alunos, eles começaram a opinar sobre as relações apreendidas e os sentidos presentes na canção de forma bastante ativa, com uma interação muito maior do que visto anteriormente.

Defendemos, como já dissemos, o direito dos alunos à interpretação e à autoria. Para criar condições de assunção da autoria, faz-se necessário instaurar o discurso polêmico (ORLANDI, 1996), pois com esse funcionamento discursivo os alunos podem disputar os sentidos, podem posicionar-se diante de um texto, podem exercer gestos de interpretação, condições que para nós não podem ser confundidas como [sic] "bagunça", indisciplina.

No dado (4), Fulano e Beltrano são nomes de estagiários e a citação direta que vem abaixo é um trecho de seu relatório. O relatório é um discurso citado (11) cuja inserção no texto do autor serve para ilustrar uma asserção que, na verdade, é apresentada como sendo do autor do artigo (L) - a de que o "discurso polêmico", tal como definido por Orlandi, cria condições para a assunção da autoria na escola.

O problema aqui é que o autor não coloca em questão o fato de os estagiários não fornecerem nenhuma informação concreta sobre as "opiniões" manifestas pelos alunos ou os "sentidos" que atribuíram ao texto; em outras palavras, não levanta a hipótese de aquilo que os estagiários definem como "não-bagunça" possa ser outra coisa senão aquilo que eles dizem ser (e que não é claramente definido no trecho de 
relatório citado dentro do fragmento 5). Dessa forma, embora o uso de um verbo como "defendemos" possa dar a entender que o que se segue é a posição assumida pelo locutor L ao comentar o dado (11), o fato de a expressão "por nós" ser usada para introduzir uma retomada das palavras de 11 ("bagunça", entre aspas) permite supor que o "nós" do verbo "defendemos" seja composto por L +11 . Em outras palavras, o relatório não é citado como dado a ser analisado, mas como discurso que vem em reforço do discurso de L.

Nesse sentido, de forma parecida com o que se viu no excerto 2, o relatório citado dentro do excerto 5 não tem o papel de dado; a relação com o discurso de L é mais semelhante ao que Ducrot define como "autoridade polifônica" (1987c), em que uma voz é introduzida no discurso mais à guisa de "garantia" de uma asserção posterior de L.

Vejamos agora nosso último exemplo, com o qual ilustramos, em um texto acadêmico, o problema de se apresentar uma conclusão a respeito da escola de forma arbitrária, sem que se demonstre com clareza ou de forma convincente como essa conclusão derivaria de algum dado concretamente observado.

(6) Seguem excertos que nos possibilitam acompanhar seus processos de inserção na escola e seus desdobramentos nas relações estabelecidas em seu cotidiano.

Definiria meu papel de observadora em sala com aquele velho jargão 'foi uma experiência e tanto'. Não pensei que esse mínimo contato com a sala de aula mexeria tanto comigo. Passei por experiências incríveis e quero relatá-las. Resumidamente, descreverei as atividades que foram designadas a mim pela professora e, em seguida, contarei algumas das minhas reflexões.

A professora pediu que eu sentasse na última carteira em um dos cantos da sala. Confesso que pouco fiquei por lá, apenas nos momentos de novas explicações e na realização de provas. Em todas as minhas visitas, dei visto nas tarefas de casa no caderno de todos os alunos, de carteira em carteira, de um por um. Também acompanhava as atividades que eram desenvolvidas pela turma. A professora dizia à classe que se tivessem dúvidas poderiam chamar a ela ou a mim. Então nós ficávamos caminhando pela sala atendendo aos alunos. (Didática, 2005)

$(\ldots)$

Nos extratos transcritos, ao observarmos suas formas de referenciação, podemos acompanhar, tendo em vista o modo de remissão textual anafórica, um movimento de aproximação e de cumplicidade dos estudantes com os sujeitos da escola, principalmente em relação às professoras de classe. Em alguns dos enunciados, na retomada de referentes, esta é feita em primeira pessoa do plural, incluindo na narração, tanto a si mesmos como também aqueles a quem se referem que, no caso específico, se volta à figura da professora. Esse recurso textual nos dá pistas de um dos sentidos atribuídos pelos estagiários à relação construída na escola com a professora. Por meio de suas narrativas, criam um cenário em que se sentem incluídos nas práticas pedagógicas de que participam ao mesmo tempo em que incluem a professora nas ações que relatam: "A professora dizia à classe que se tivessem dúvidas poderiam chamar a ela ou a mim. Então nós ficávamos caminhando pela sala atendendo aos alunos" e "durante meu 
estágio no C., eu e a professora A., tivemos a ideia de montarmos com as crianças um dicionário (negritos nossos, itálicos no original)

$\mathrm{Na}$ passagem acima, o autor introduz um conjunto de dados a serem analisados com uma afirmação geral sobre o que poderemos encontrar neles ("processos de inserção na escola e seus desdobramentos nas relações estabelecidas em seu cotidiano"). Na sequência, são mostrados três trechos de relatórios, dois quais transcrevemos apenas o primeiro ("Definiria meu papel..." até "...(Didática, $\left.2005)^{\prime \prime}\right)$. Os trechos citados no original ocupam 37 linhas na diagramação do artigo, compondo, portanto, uma amostra extensa. Quando o autor retoma a palavra após essas 37 linhas, afirma que há "formas de referenciação" nos dados, mas não se refere de maneira mais pontual ao local em que essas formas podem ser encontradas; o mesmo vale para a afirmação sobre a "remissão textual anafórica". A frase seguinte faz uma afirmação mais específica, de que um referente é retomado "em primeira pessoa do plural", mas o referente dessa afirmação é situado de maneira genérica ("em alguns enunciados"). Ao fim do parágrafo, o autor finalmente recorta duas passagens dos dados. Da maneira como o texto está construído, pode-se entender que essas passagens consistem em exemplos das afirmações anteriores, e neste caso deixa-se a cargo do leitor localizar outras passagens em que a mesma afirmação seja válida. Como o autor não diz explicitamente que se trata de exemplos, no entanto, pode-se supor também que a análise apresentada no início do parágrafo refere-se exclusivamente a essas duas passagens.

Um primeiro aspecto do problema presente aqui consiste, como podemos ver, no fato de que a conclusão apresentada pelo autor - de que teria havido um "movimento de aproximação e cumplicidade" dos estagiários com relação aos "sujeitos da escola" - é extraída de uma amostra extensa de dados dentro dos quais não se aponta com precisão as evidências daquilo que se afirma. Quando se procura pontuar os elementos a partir dos quais o autor teria chegado a sua conclusão, encontra-se um segundo aspecto do problema. Entre as duas passagens destacadas pelo autor, apenas na primeira há uma remissão textual anafórica - o sintagma "a ela ou a mim" é retomado pelo pronome "nós" (observe-se que o autor destaca todo o sintagma "nós ficávamos" como sendo um elemento anafórico). A segunda passagem apontada como contendo uma anáfora ilustra um caso de concordância - "eu e a professora A." seria o sujeito, e o predicado seria iniciado por "tivemos" - ou de topicalização - "eu e a professora A." seria o tópico, e "tivemos..." seria o comentário. $\mathrm{O}$ único caso em que se poderia considerar que há uma remissão anafórica nesse trecho é se considerarmos que a frase está estruturada como tópicocomentário e que há um sujeito "nós" elíptico antes do verbo "tivemos". Trata-se, 
portanto, de um uso bastante impreciso dos conceitos apresentados no trabalho como sendo parte da sustentação da pesquisa. Um terceiro e último aspecto a se levar em conta é o fato de o autor apresentar, sem maiores explicações, a ideia de que a "referenciação" (um procedimento de construção do texto) serviria como evidência de uma "aproximação" e "cumplicidade dos estudantes com os sujeitos da escola" (movimentos ou estados atribuídos aos alunos e não ao texto). Não há maiores discussões sobre como se faz a passagem de um âmbito ao outro.

Podemos descrever o que acontece nessa passagem dizendo que o texto citado como objeto de comentário é lido pelo autor a partir de dois pontos de vista diferentes: o do linguista (E1), que o analisa como dado de linguagem; e o do formador (E2), que o lê como evidência de um processo formativo. Toda a fragilidade da conclusão apresentada resulta da forma particular como esses dois pontos de vista coexistem no enunciado - não caminham para uma síntese, nem se mostram enquanto polos dialéticos ou polêmicos. Há mais, no entanto. Apenas um desses pontos de vista é explicitamente declarado ao leitor e caracterizado em termos dos conceitos que o fundamentam ou do modo como opera: o do linguista (E1). O segundo olhar, do qual emana justamente a apreciação do autor sobre o resultado formativo do estágio, não é apresentado ao leitor com o mesmo cuidado. Há, portanto, um ethos muito particular por meio do qual o autor se permite entremear a análises teóricas razoavelmente sistematizadas outros comentários de cunho aparentemente passageiro que, entretanto, são mais decisivos do que as conclusões trazidas pela teoria em si. Um sujeito teórico conduz uma parte do discurso, mas parece funcionar mais como escudo ou distração para o leitor, de forma que, enquanto o raciocínio do linguista (E1) se desenrola de maneira anunciada, os pontos de vista do formador (E2) são introduzidos de forma quase sub-reptícia.

\section{CONSIDERAÇÕES FINAIS}

Apresentamos aqui três problemas encontrados na produção escrita da área de ensino de língua, seja em relatórios produzidos por estudantes ou em trabalhos publicados em veículos acadêmicos: a) o uso de certos termos inespecíficos permite que o autor não apresente dados ou não especifique, para si ou para outros, determinadas ideias nas quais o seu discurso se fundamenta; b) as palavras dos agentes escolares são citadas de tal forma que se responde a elas de fora de um enquadre teórico-metodológico no qual possam ser manejadas enquanto dados; 
c) apresentam-se conclusões arbitrárias, cuja relação com os dados efetivamente mostrados, quando os há, é confusa ou refutável.

Esses três problemas podem ser sintetizados em uma única formulação: a aula, mesmo quando registrada, frequentemente não é tratada enquanto dado no discurso da pesquisa sobre ensino. Com isso queremos retomar nossa afirmação de que o ponto nodal de onde derivam os problemas que vimos apontando está na forma como esses discursos "escutam" as vozes das quais poderiam extrair seus dados - enunciados de professores, alunos e outros agentes escolares; livros e materiais escolares etc. -, conferindo-lhes estatutos e papéis flutuantes, por vezes não explicitados.

Esta percepção nos parece importante, em primeiro lugar, na medida em que aponta para alguns parâmetros a serem considerados quando se exige do professor em formação que escreva a respeito de suas experiências práticas na escola. Parece-nos necessário que, na produção de relatórios de estágio e documentos afins, o registro dos acontecimentos em sala seja encarado mais claramente como produção de um dado a ser analisado e não apenas como testemunho ou relato de uma vivência particular. Ao mesmo tempo, parece-nos necessário empreender uma discussão a respeito da própria configuração do campo do ensino de língua no Brasil, e em especial acerca do que essa área vem logrando produzir em termos de conhecimento dos problemas específicos enfrentados pelos professores e da realidade cotidiana do ensino. A fragilidade do tratamento conferido aos dados em discursos representativos do campo da pesquisa em ensino pode estar mostrando que a bibliografia destinada aos futuros professores não está suficientemente próxima do acontecimento da aula para dar conta das questões que efetivamente emergem da prática.

\section{REFERÊNCIAS BIBLIOGRÁFICAS}

BAKHTIN, Mikhail. Marxismo e filosofia da linguagem. Tradução de Michel Lahud e Yara Frateschi Vieira. 11 ${ }^{\text {a }}$ edição. São Paulo: Hucitec, 2004.

CAREL, Marion; DUCROT, Oswald. Atualização da polifonia (Mise au point sur la polyphonie). Revista do Programa de Pós-Graduação em Letras da Universidade de Passo Fundo, v. 6, n. 1, p. 9-21, jan/jun. 2010.

DUCROT, Oswald. Esboço de uma teoria polifônica da enunciação. In: O dizer e o dito. Campinas: Pontes, 1987a, p. 161-218

DUCROT, Oswald. Pressupostos e subentendidos: a hipótese de uma semântica linguística. In: O dizer e o dito. Campinas: Pontes, 1987b, p. 13-30. 
DUCROT, Oswald. A argumentação por autoridade. In: O dizer e o dito. Campinas: Pontes, 1987c, p. 139-159.

DUCROT, Oswald e CAREL, Marion. Descrição argumentativa e descrição polifônica: o caso da negação. Letras de Hoje, Porto Alegre, v. 43, n. 1, p. 7-18, jan/mar. 2008.

PÊCHEUX, Michel. Semântica e discurso. Uma crítica à afirmação do óbvio. Tradução de Eni Pulcinelli Orlandi [et al.]. 2a edição. Campinas: Unicamp, 1995.

Recebido: 30/08/2015

Aceito: 15/07/2016 